\title{
Efficacy of abiraterone combined with flutamide on prostate cancer patients and its effect on serum miR-493-5p and miR-195-5p
}

\author{
CHUNYAN YANG ${ }^{1}$, YANLING DAI $^{2}$, SHUHUA PANG $^{3}$ and XIAOMIN GUO ${ }^{4}$ \\ ${ }^{1}$ Department of Pharmacy and ${ }^{2}$ Laboratory Department, Chuxiong Medical College, Chuxiong, Yunnan 675000; \\ ${ }^{3}$ Clinical Laboratory, Longhua Hospital Shanghai University of Traditional Chinese Medicine, Shanghai 200000; \\ ${ }^{4}$ School of Nursing, Chuxiong Medical College, Chuxiong, Yunnan 675000, P.R. China
}

Received July 10, 2019; Accepted December 16th, 2019

DOI: $10.3892 / \mathrm{ol} .2020 .11719$

\begin{abstract}
Efficacy of abiraterone combined with flutamide on patients with prostate cancer (PCa) and its effect on levels of miR-493-5p and miR-195-5p contained in serum were investigated. The medical records of $146 \mathrm{PCa}$ patients admitted to Longhua Hospital Shanghai University of Traditional Chinese Medicine from January 2011 to December 2013 were selected. Eighty-four patients were treated with abiraterone combined with flutamide as a study group, 62 patients were treated with abiraterone alone as a control group. The curative effect, adverse reactions, quality of life and five-year overall survival (OS) of the two groups were compared. The serum prostate-specific antigen (PSA) level was measured by radioimmunoassay at 3 days (T1) before treatment, 1 month (T2), 2 months (T3), and 6 months (T4) after treatment, and the relative expression of miR-493-5p and miR-195-5p in serum were detected by qRT-PCR. The total effective rate of the study group was significantly higher than that of the control group $(\mathrm{P}<0.05)$. The total incidence of toxic and side effects in the study group was significantly lower than that in the control group $(\mathrm{P}<0.05)$. The improvement rate of quality of life in the study group was significantly higher than that in the control group $(\mathrm{P}<0.05)$. OS in the study group was significantly higher than that in the control group at 5 years $(\mathrm{P}<0.05)$. There was no significant difference in serum PSA level between the two groups at T1 $(\mathrm{P}>0.05)$; there was no significant difference in the relative expression of miR-493-5p and miR-195-5p between the two groups at $\mathrm{T} 1(\mathrm{P}>0.05)$. In conclusion, abiraterone combined with flutamide has better curative effect and lower incidence of adverse reactions in patients with metastatic castrationresistant $\mathrm{PCa}(\mathrm{CRPC})$ than abiraterone alone, and can increase
\end{abstract}

Correspondence to: Dr Xiaomin Guo, School of Nursing, Chuxiong Medical College, New Avenue, Donggua, Chuxiong, Yunnan 675000, P.R. China

E-mail: gltf76@163.com

Key words: abiraterone, flutamide, PCa, miR-493-5p, miR-195-5p the expression levels of miR-493-5p and miR-195-5p in patient serum.

\section{Introduction}

Prostate cancer (PCa) is a common malignant tumor of genitourinary system in clinic (1). In recent years, prostate-specific antigen (PSA) screening is widely used in PCa examination, so the diagnosis rate and treatment rate of early $\mathrm{PCa}$ also increase (2). PCa is the second most common malignant tumor in men after lung cancer. It is estimated that more than one million new cases are diagnosed every year in the world (3), and the incidence rate is increasing (4). After the primary treatment of chemical or surgical castration for $\mathrm{PCa}$ patients, most cases would develop into disease state, which is the metastatic castration-resistant prostate cancer (CRPC), with median survival less than 2 years (5). For the treatment of CRPC, androgen pathway inhibitors have become the mainstream treatment method in recent years, such as flutamide, sipuleucel-T, enzalutamide, abiraterone acetate, radium-223 and cabazitaxel, which can provide survival benefits for CRPC patients (6).

Abiraterone is a selective and irreversible cytochrome $\mathrm{P} 450$ c17 (CYP17) inhibitor. With potency 10 to 30 times higher than ketoconazole, it is a non-selective inhibitor. CYP17 plays an important role in androgen synthesis and is a key enzyme in testosterone synthesis (7). Abiraterone acetate is a prodrug of abiraterone and a selective inhibitor of androgen biosynthesis, which effectively blocks CYP17 and androgen synthesis in adrenal gland, testis and prostate tumors (8). Flutamide is a non-steroidal oral antiandrogen that blocks the effect of testosterone. Testosterone is a natural hormone responsible for the growth and diffusion of human PCa cells. Blocking the effect of testosterone can slow down the growth and diffusion of $\mathrm{PCa}$ cells. Currently, it has been widely used in treating patients with PCa $(9,10)$.

MicroRNA (miRNA) is a newly discovered class of highly conserved endogenous non-coding hairpin nucleotide transcripts with a length of approximately 19-25 bases and widely existing in eukaryotic cells $(11,12)$. Studies have found that some miRNAs are closely related to the occurrence and 
development of cancer. For example, the research results of Beebe-Dimmer et al (13) show that miR-195-5p is downregulated in PCa cell lines DU145 and PC3. Overexpression of miR-195-5p significantly inhibits the migration and invasion of PCa cells, and they have proved that miR-195-5p can inhibit PCa cell movement by regulating the expression of c-Met, MMP1 and MMP9. Research results of Zhao et al (14) show that miR-493-5p is downregulated in breast cancer cells and plays an inhibitory role in invasion and tumorigenicity of breast cancer cells. Human miR-493-5p belongs to DLK1-DIO3 imprinted miRNA clusters and plays a role as a tumor inhibitor in human cancers (14). Wang et al (15) showed that miR-493-5p is a tumor suppressor gene and is downregulated in human liver cancer. Overexpression of miR-493-5p promotes apoptosis and inhibits proliferation and migration of liver cancer cells by negatively regulating VAMP expression. The research results of Wang et al (15) show that miR-493-5p is downregulated in PCa cells and acts as a tumor inhibitor in PCa cells.

At present, there are many studies on the treatment of PCa patients with single drug use of abiraterone and flutamide, but there are few on the treatment of PCa patients with abiraterone combined with flutamide. This study aimed to find more effective and safer treatment drugs for $\mathrm{PCa}$ patients, to prolong the survival time of patients and improve the quality of life through the efficacy and adverse reactions of abiraterone combined with flutamide in the treatment of PCa patients, as well as the effects on expression of miR493-5p and miR-195-5p.

\section{Patients and methods}

General information. The medical records of $146 \mathrm{PCa}$ patients were selected, who were admitted to Longhua Hospital Shanghai University of Traditional Chinese Medicine (Shanghai, China) from January 2011 to December 2013. Among them, 84 patients were treated with abiraterone combined with flutamide as a study group, and 62 patients were treated with abiraterone alone as a control group.

Inclusion and exclusion criteria. Inclusion criteria were as follows: Patients were confirmed as PCa by pathological examination in both groups; PSA progress was observed in both groups; both groups of patients were male, aged 18-60 years. Exclusion criteria were as follows: patients with mental illness and other serious diseases; patients allergic to the drugs used in this study; patients who used targeted therapy of enzarumine or other similar potent androgen pathways.

Patients and their families were informed and signed informed consent forms. This study was approved by the Medical Ethics Committee of Longhua Hospital Shanghai University of Traditional Chinese Medicine.

Main instruments and reagents. Human PSA kit (Cusabio); multifunctional microplate reader (model: DLK0001622, BioTek Instruments, Inc.); real-time fluorescence quantitative PCR instrument (model: 7300, Applied Biosystems; Thermo Fisher Scientific, Inc.); spectrophotometer (model: DR5000, Hach Company); high-speed refrigerated centrifuge (Eppendorf); TRIzol kit (BioTek Instruments, Inc.); reverse transcription kit (Takara); real-time fluorescence quantitative PCR kit (Beijing BioDee BioTech Corporation Ltd.); miR493-5p, miR-195-5p and U6 small nuclear RNA (RNU6B) internal reference primers were designed and synthesized by GeneCopoeia, Inc. The detailed primer sequences are shown in Table I.

Treatment methods. Control group: patients were given $1,000 \mathrm{mg}$ of abiraterone acetate orally (Xian Janssen Pharmaceutical Ltd., SFDA approval no. J20150112), once a day; study group: on the basis of the control group, the patients in the study group were given $250 \mathrm{mg}$ of flutamide orally (Tasly Diyi Pharmaceutical Co., Ltd., SFDA approval no. H19990143) once a day. Altogether 28 days as a cycle, two groups of patients were treated for 4 consecutive cycles.

Observation index and therapeutic effect evaluation standard. The efficacy evaluation was divided into four parts according to the World Health Organization solid tumor evaluation standard (16): complete response (CR) is defined as complete disappearance of tumor focus and no new focus; partial response $(\mathrm{PR})$ is defined as the degree of volume reduction of tumor lesions $>50 \%$; stable disease (SD) is defined as the reduction of tumor focus volume $<50 \%$; progressive disease (PD) is defined as the degree of tumor lesion volume increase above $25 \%$. The overall response rate $(\mathrm{ORR})=(\mathrm{CR}+\mathrm{PR}) /$ Total cases $\mathrm{x} 100 \%$. The toxic and side effects of group A and group B during treatment were observed. The main toxic and side effects were nausea, vomiting, anemia, thrombocytopenia, myelosuppression, liver function injury and renal function injury.

According to Karnofsky (KPS) score (17), the quality of life of patients after treatment was evaluated. After treatment, KPS score was improved by $>10$ points, which is classified as improvement. After treatment, KPS score was decreased or increased by less than 10 points, which is classified as stability. After treatment, KPS score was decreased by $>10$ points, which is classified as deterioration. Quality of Life Improvement Rate $=($ Improvement + Stability $) /$ Total cases $\mathrm{x} 100 \%$.

Follow-up. The two groups of patients were followed up by telephone and visit for 5 years. The follow-up was conducted once every 3 months within 5 years, with the deadline of January 2019. The overall survival (OS) was calculated from the beginning of drug administration to the day of death or the last follow-up in both groups.

Serum standard collection. A total of $5 \mathrm{ml}$ fasting venous blood of the two groups of patients was sampled and placed in EDTA-K2 anticoagulation tube three days before treatment (T1), one month after treatment (T2), two months after treatment (T3) and six months after treatment (T4). The samples were centrifuged at $1,500 \mathrm{x}$ g at $4^{\circ} \mathrm{C}$ for $10 \mathrm{~min}$, and $500 \mu \mathrm{l}$ of upper serum was drawn and stored in EP tube for later use.

Detection of serum PSA level. The serum PSA levels of the two groups of patients were determined by radioimmunoassay at T1, T2, T3 and T4. The detection process was strictly conducted according to the PSA kit instructions. 
Table I. Sequence of primers.

\begin{tabular}{lll}
\hline Gene & \multicolumn{1}{c}{ Upstream primer sequence } & \multicolumn{1}{c}{ Downstream primer sequence } \\
\hline miR-493-5p & 5'-TCCTACGGAGAGGCTCAG-3' & 5'-TCCTCGTAGTCCAACACG-3' \\
miR-195-5p & 5'-CGTAGCAGCACAGAAA-3' & 5'-GTGCAGGGTCCGGGT-3' \\
U6 & 5'-CTCGCTTCGGCAGCACA-3' & 5'-AACGCTTCACGAATTTGCGT-3' \\
\hline
\end{tabular}

Table II. Comparison of general data of both groups [n (\%)].

\begin{tabular}{|c|c|c|c|c|}
\hline Group & Control group $(n=62)$ & Study group $(n=84)$ & $\chi^{2}$ value & P-value \\
\hline Age & & & 0.311 & 0.577 \\
\hline$<45$ & $23(37.10)$ & $35(41.67)$ & & \\
\hline$\geq 45$ & $39(62.90)$ & $49(58.33)$ & & \\
\hline Smoking history & & & 0.877 & 0.349 \\
\hline Yes & $47(75.81)$ & $69(82.14)$ & & \\
\hline No & $15(24.19)$ & $15(17.86)$ & & \\
\hline Exercise & & & 0.835 & 0.361 \\
\hline Yes & $36(58.06)$ & $55(65.48)$ & & \\
\hline No & $26(41.94)$ & $29(34.52)$ & & \\
\hline Residence & & & 1.086 & 0.297 \\
\hline Urban & $40(64.52)$ & $47(55.95)$ & & \\
\hline Rural & $22(35.48)$ & $37(44.05)$ & & \\
\hline Ethnicity & & & 0.673 & 0.412 \\
\hline Han & 57 (91.94) & $80(95.24)$ & & \\
\hline Minority & $5(8.06)$ & $4(4.76)$ & & \\
\hline Education level & & & 1.331 & 0.249 \\
\hline$<$ High school & $46(74.19)$ & $57(67.86)$ & & \\
\hline$\geq$ High school & $16(25.81)$ & $27(32.14)$ & & \\
\hline Weight & & & 1.041 & 0.308 \\
\hline$<55 \mathrm{~kg}$ & $25(40.32)$ & $27(32.14)$ & & \\
\hline$\geq 55 \mathrm{~kg}$ & 37 (59.68) & $57(67.86)$ & & \\
\hline Diet preference & & & 0.819 & 0.366 \\
\hline Light & $33(53.23)$ & $51(60.71)$ & & \\
\hline Spicy & $29(46.77)$ & 33 (39.29) & & \\
\hline Alcohol consumption & & & 0.199 & 0.656 \\
\hline Never or seldom & $16(25.81)$ & $19(22.62)$ & & \\
\hline Frequent & 46 (74.19) & $65(77.38)$ & & \\
\hline
\end{tabular}

Detection of serum miR-493-5p and miR-195-5p. At T1, T2, T3 and T4, the serum of the two groups of patients was taken for miR-493-5p and miR-195-5p detection, and the specific steps were as follows: the serum total RNA was extracted according to the instructions of the TRIzol serum extraction kit. Total RNA purity, concentration and integrity were determined by UV spectrophotometry and agarose gel electrophoresis. Total RNA $(2 \mu \mathrm{l})$ was taken to prepare cDNA according to the instruction manual of the kit. The reverse transcription reaction conditions were as follows: $42^{\circ} \mathrm{C}$ for $60 \mathrm{~min}$ and $95^{\circ} \mathrm{C}$ for $5 \mathrm{~min}$; the synthesized cDNA sample was stored at $-20^{\circ} \mathrm{C}$ for later use. U6 was used as the internal reference gene, and the reaction system of the total volume $(20 \mu 1)$ was as follows: $1 \mu \mathrm{l}$ of cDNA, $10 \mu \mathrm{l}$ of PCR premix, $2 \mu \mathrm{l}$ of upstream primer (x10), $2 \mu \mathrm{l}$ of downstream primer (x10), and $5 \mu \mathrm{l}$ of dd water (Rnase and Dnase free). PCR amplification cycle conditions were as follows: $90^{\circ} \mathrm{C}$ for $5 \mathrm{~min}, 90^{\circ} \mathrm{C}$ for $5 \mathrm{sec}, 60^{\circ} \mathrm{C}$ for $30 \mathrm{sec}, 72^{\circ} \mathrm{C}$ for $5 \mathrm{sec}$, a total of 40 cycles. Amplification data were analyzed by ABI PRISM 7500 fluorescence quantitative PCR instrument manufacturer software, and the results were expressed by $2^{-\Delta \mathrm{CT}}$.

Statistical method. SPSS 21.0 (Easybio) was used for analysis, and GraphPad Prism 7 was used to visualize the data. In this study, the counting data were expressed by [n (\%)], and Chi-square test was used to compare the rates. 
Table III. Comparison of clinical efficacy results of two groups of patients [n (\%)].

\begin{tabular}{|c|c|c|c|c|}
\hline Group & Control group $(n=62)$ & Study group $(n=84)$ & $\chi^{2}$ value & $\mathrm{P}$-value \\
\hline CR & $8(12.90)$ & $14(16.67)$ & - & - \\
\hline PR & $15(24.19)$ & $34(40.48)$ & - & - \\
\hline SD & $29(46.77)$ & $26(30.95)$ & - & - \\
\hline PD & $10(16.13)$ & $10(11.91)$ & - & - \\
\hline RR & $23(37.10)$ & $48(57.14)$ & 5.738 & 0.017 \\
\hline
\end{tabular}

Table IV. Comparison of adverse reactions between two groups of patients [n (\%)].

\begin{tabular}{|c|c|c|c|c|}
\hline Group & Control group $(n=62)$ & Study group $(n=84)$ & $\chi^{2}$ value & P-value \\
\hline Nausea and vomiting & $3(4.84)$ & $3(3.57)$ & 0.145 & 0.703 \\
\hline Anemia & $4(6.45)$ & $2(2.38)$ & 1.500 & 0.221 \\
\hline Thrombocytopenia & $3(4.84)$ & $2(2.38)$ & 0.652 & 0.807 \\
\hline Myelosuppression & $5(8.06)$ & $4(4.76)$ & 0.673 & 0.412 \\
\hline Liver function injury & $2(3.23)$ & $1(1.19)$ & 0.734 & 0.392 \\
\hline Renal function injury & $3(4.84)$ & $1(1.19)$ & 1.782 & 0.128 \\
\hline Total incidence rate & $20(32.26)$ & $13(15.48)$ & 5.743 & 0.017 \\
\hline
\end{tabular}

The measurement data were expressed as mean \pm standard deviation (mean $\pm \mathrm{SD}$ ). $\mathrm{t}$-test was used for comparison of measurement data between two groups, and one-way analysis of variance was used for the comparison of multiple groups. Kaplan-Meier method was used to draw five-year OS curves of the two groups of patients, and log-rank test for comparison. $\mathrm{P}<0.05$ was considered to indicate a statistically significant difference.

\section{Results}

Comparison of general data between two groups of patients. There was no significant difference between the control group and the study group in age, smoking history, exercise, residence, ethnicity, education level, weight, diet preference, and alcohol consumption $(\mathrm{P}>0.05)$ (Table II).

Clinical efficacy of two groups of patients. In the control group after treatment, there were 8 cases of CR $(12.91 \%)$, 15 cases of PR (24.19\%), 29 cases of SD (46.77\%), 10 cases of PD $(16.13 \%)$, response rate (RR) was $37.10 \%$. In the study group after treatment, there were 14 cases of CR (16.66\%), 34 cases of PR (40.48\%), 26 cases of SD (30.95\%), 10 cases of PD (11.91\%), and RR was $57.14 \%$. RR of study group was significantly higher than that of control group $(\mathrm{P}<0.05)$ (Table III).

Comparison of toxic and side effects between two groups of patients. During the treatment, toxic and side effects occurred in both groups, and there was no allergic reaction. In the control group, nausea and vomiting occurred in 3 cases $(4.84 \%)$, anemia in 4 cases $(6.45 \%)$, thrombocytopenia in 3 cases $(4.84 \%)$, myelosuppression in 5 cases $(8.06 \%)$, liver function injury in 2 cases $(3.23 \%)$, renal function injury in 3 cases $(4.84 \%)$, and the total incidence of toxic and side effects was $32.26 \%(20 / 62)$. In the study group, nausea and vomiting occurred in 3 cases $(3.57 \%)$, anemia in 2 cases $(2.38 \%)$, thrombocytopenia in 2 cases $(2.38 \%)$, myelosuppression in 4 cases $(4.76 \%)$, liver function injury in 1 case $(1.19 \%)$, renal function injury in 1 case $(1.19 \%)$, and the total incidence of adverse reactions was $15.48 \%$ (13/84). There was no significant difference in the incidence of nausea, vomiting, anemia, thrombocytopenia, bone marrow suppression, liver function injury and renal function injury between the two groups ( $P>0.05)$, but the total incidence of adverse reactions in the study group was significantly lower than that in the control group $(\mathrm{P}<0.05)($ Table IV).

Comparison of quality of life between two groups of patients. The quality of life in the control group was improved in 10 cases $(15.63 \%)$, stabilized in 25 cases $(39.06 \%)$, deteriorated in 29 cases $(45.31 \%)$, and the improvement rate of quality of life was $54.69 \% 30$ days after discharge. In the study group, the quality of life was improved in 16 cases (19.05\%), stabilized in 46 cases $(54.76 \%)$, deteriorated in 22 cases $(26.19 \%)$, and the improvement rate of quality of life was $73.81 \% 30$ days after treatment. The improvement rate of quality of life in the study group was significantly higher than that in the control group $(\mathrm{P}<0.05)($ Table $\mathrm{V})$.

Comparison of 5-year survival rate between two groups of patients. The follow-up results showed that OS in the study group was $45.24 \%(38 / 84)$ at 5 years and OS in the control group was $20.97 \%(13 / 62)$ at 5 years. OS in the study group was significantly higher than that in the control group at 5 years $(\mathrm{P}<0.05)$ (Fig. 1).

Comparison of serum PSA levels of two groups of patients at different time points. There was no significant difference 
Table V. Comparison of quality of life between two groups of patients [n (\%)].

\begin{tabular}{lccccc}
\hline Group & $\mathrm{n}$ & Improved & Stabilized & Deteriorated & Improvement rate $(\%)$ \\
\hline Control group & 62 & $10(15.63)$ & $25(39.06)$ & $29(45.31)$ & 54.69 \\
Study group & 84 & $16(19.05)$ & $46(54.76)$ & $22(26.19)$ & 73.81 \\
$\chi^{2}$ value & - & - & - & - & 6.649 \\
P-value & - & - & - & - & 0.001
\end{tabular}

Table VI. Comparison of serum PSA levels of two groups of patients at different time points (mean $\pm \mathrm{SD}, \mathrm{ng} / \mathrm{ml}$ ).

\begin{tabular}{lcccccc}
\hline Group & $\mathrm{n}$ & $\mathrm{T} 1$ & $\mathrm{~T} 2$ & $\mathrm{~T} 3$ & $\mathrm{~T} 4$ & $\mathrm{~F}$ \\
\hline Control group & 62 & $63.42 \pm 22.13$ & $5.82 \pm 1.87^{\mathrm{a}}$ & $4.21 \pm 1.23^{\mathrm{a}, \mathrm{b}}$ & $6.46 \pm 1.52^{\mathrm{a}-\mathrm{c}}$ & 418.944 \\
Study group & 84 & $64.14 \pm 19.24$ & $4.65 \pm 1.31^{\mathrm{a}}$ & $3.44 \pm 0.87^{\mathrm{a}, \mathrm{b}}$ & $4.13 \pm 0.93^{\mathrm{a}-\mathrm{c}}$ & 811.626 \\
t value & - & 0.210 & 4.446 & 4.431 & 11.450 & $<0.001$ \\
P-value & - & 0.834 & $<0.001$ & $<0.001$ & $<0.001$ & - \\
\hline
\end{tabular}

Compared with $\mathrm{T} 1,{ }^{\mathrm{a}} \mathrm{P}<0.05$ compared with $\mathrm{T} 2$, ${ }^{\mathrm{b}} \mathrm{P}<0.05$ compared with $\mathrm{T} 3,{ }^{\mathrm{c}} \mathrm{P}<0.05$. $\mathrm{T} 1$, three days before treatment; $\mathrm{T} 2$, one month after treatment; T3, two months after treatment; T4, six months after treatment.

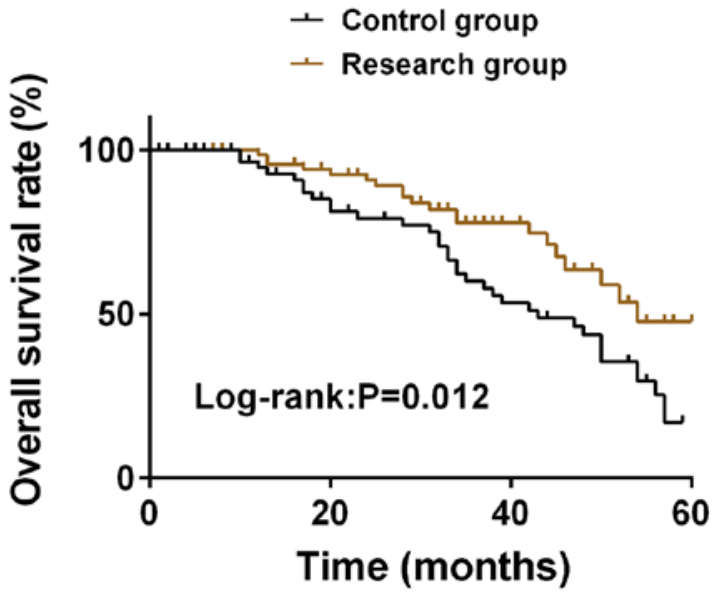

Figure 1. Comparison of quality of life between the two groups. The followup results showed that OS in the study group was significantly higher than that in the control group at 5 years $(\mathrm{P}<0.05)$. OS, overall survival.

in serum PSA level between the two groups at $\mathrm{T} 1(\mathrm{P}>0.05)$. Compared with T1, serum PSA levels in T2, T3 and T4 groups were significantly decreased $(\mathrm{P}<0.05)$. Compared with $\mathrm{T} 2$, the serum PSA level of the two groups of patients decreased significantly at $\mathrm{T} 3(\mathrm{P}<0.05)$, while the serum PSA level of the study group decreased significantly at $\mathrm{T} 4(\mathrm{P}<0.05)$, and the serum PSA level of the control group increased significantly $(\mathrm{P}<0.05)$. Compared with $\mathrm{T} 3$, the serum PSA levels of the two groups at T4 were significantly increased $(\mathrm{P}<0.05)$. At T2, T3 and T4, the serum PSA level in the study group was significantly higher than that in the control group $(\mathrm{P}<0.05)$. There was no significant difference in serum PSA level between the two groups at $\mathrm{T} 1(\mathrm{P}>0.05)$. Compared with $\mathrm{T} 1$, the serum PSA levels of the two groups of patients at T2, $\mathrm{T} 3$ and $\mathrm{T} 4$ were significantly decreased $(\mathrm{P}<0.05)$, and the study group was significantly lower than the control group $(\mathrm{P}<0.05)$ (Table VI).

Comparison of relative expression of serum miR-493-5p in two groups of patients at different time points. There was no significant difference in the relative expression of serum miR493-5p between the two groups at T1 ( $\mathrm{P}>0.05)$. Compared with $\mathrm{T} 1$, the relative expression of $\mathrm{miR}-493-5 \mathrm{p}$ in serum of the two groups of patients at T2, T3 and T4 were significantly increased $(\mathrm{P}<0.05)$. Compared with $\mathrm{T} 2$, the relative expression levels of serum miR-493-5p at T3 and T4 were significantly increased $(\mathrm{P}<0.05)$. Compared with $\mathrm{T} 3$, the relative expression of serum miR-493-5p in the two groups at T4 was significantly increased $(\mathrm{P}<0.05)$. At $\mathrm{T} 2, \mathrm{~T} 3$ and $\mathrm{T} 4$, the relative expression of serum miR-493-5p in the study group was significantly higher than that in the control group $(\mathrm{P}<0.05)$ (Table VII).

Comparison of serum miR-195-5p relative expression in two groups of patients at different time points. There was no significant difference in the relative expression of serum miR195-5p between the two groups at T1 ( $>>0.05)$. Compared with $\mathrm{T} 1$, the relative expression of $\mathrm{miR}-195-5 \mathrm{p}$ in serum at $\mathrm{T} 2$, $\mathrm{T} 3$ and T4 was significantly increased in both groups $(\mathrm{P}<0.05)$. Compared with T2, the relative expression of miR-195-5p in serum at T3 and T4 was significantly increased in both groups $(\mathrm{P}<0.05)$. Compared with $\mathrm{T} 3$, the relative expression of serum miR-195-5p in the two groups at T4 was significantly increased $(\mathrm{P}<0.05)$. At $\mathrm{T} 2, \mathrm{~T} 3$ and $\mathrm{T} 4$, the relative expression of serum miR-195-5p in the study group was significantly higher than that in the control group $(\mathrm{P}<0.05)$ (Table VIII).

Diagnostic value of miR-493-5p and miR-195-5p expression levels in patients. According to the clinical efficacy, the patients were divided into RR group $(n=71)$ and non-RR group $(n=75)$. The serum levels of miR-493-5p and miR-195-5p 
Table VII. Comparison of relative expression levels of serum miR-493-5p in two groups of patients at different time points $($ mean $\pm \mathrm{SD})$.

\begin{tabular}{lcccccc}
\hline Group & $\mathrm{n}$ & $\mathrm{T} 1$ & $\mathrm{~T} 2$ & $\mathrm{~T} 3$ & $\mathrm{~T} 4$ & $\mathrm{~F}$ \\
\hline Control group & 62 & $1.07 \pm 0.78$ & $1.38 \pm 0.68^{\mathrm{a}}$ & $1.62 \pm 0.57^{\mathrm{a}, \mathrm{b}}$ & $1.88 \pm 0.73^{\mathrm{a}-\mathrm{c}}$ & 14.508 \\
Study group & 84 & $1.12 \pm 0.67$ & $1.67 \pm 0.69^{\mathrm{a}}$ & $1.98 \pm 0.89^{\mathrm{a}, \mathrm{b}}$ & $2.34 \pm 0.81^{\mathrm{a}-\mathrm{c}}$ & 37.815 \\
t value & - & 0.416 & 2.526 & 2.789 & 3.535 & $<0.001$ \\
P-value & - & 0.678 & 0.013 & 0.006 & $<0.001$ & - \\
\hline
\end{tabular}

Compared with $\mathrm{T} 1,{ }^{\mathrm{a}} \mathrm{P}<0.05$ compared with $\mathrm{T} 2$, ${ }^{\mathrm{b}} \mathrm{P}<0.05$ compared with $\mathrm{T} 3,{ }^{\mathrm{c}} \mathrm{P}<0.05$. $\mathrm{T} 1$, three days before treatment; $\mathrm{T} 2$, one month after treatment; T3, two months after treatment; T4, six months after treatment.

Table VIII. Comparison of relative expression of serum miR-195-5p between two groups of patients at different time points (mean $\pm \mathrm{SD})$.

\begin{tabular}{|c|c|c|c|c|c|c|c|}
\hline Group & $\mathrm{n}$ & $\mathrm{T} 1$ & $\mathrm{~T} 2$ & T3 & $\mathrm{T} 4$ & $\mathrm{~F}$ & P-value \\
\hline Control group & 62 & $0.65 \pm 0.29$ & $1.12 \pm 0.35^{\mathrm{a}}$ & $1.43 \pm 0.45^{\mathrm{a}, \mathrm{b}}$ & $1.71 \pm 0.61^{\mathrm{a}-\mathrm{c}}$ & 65.489 & $<0.001$ \\
\hline Study group & 84 & $0.64 \pm 0.34$ & $1.59 \pm 0.41^{\mathrm{a}}$ & $1.97 \pm 0.54^{\mathrm{a}, \mathrm{b}}$ & $2.48 \pm 0.65^{\mathrm{a}-\mathrm{c}}$ & 203.549 & $<0.001$ \\
\hline $\mathrm{t}$ value & - & 0.187 & 7.278 & 6.401 & 7.261 & - & - \\
\hline P-value & - & 0.852 & $<0.001$ & $<0.001$ & $<0.001$ & - & - \\
\hline
\end{tabular}

Compared with $\mathrm{T} 1,{ }^{\mathrm{a}} \mathrm{P}<0.05$ compared with $\mathrm{T} 2,{ }^{\mathrm{b}} \mathrm{P}<0.05$ compared with $\mathrm{T} 3,{ }^{\mathrm{c}} \mathrm{P}<0.05$. $\mathrm{T} 1$, three days before treatment; $\mathrm{T} 2$, one month after treatment; T3, two months after treatment; T4, six months after treatment.

were detected in the two groups. The expression levels of miR-493-5p in RR group and non-RR group were $1.78 \pm 0.43$ and $1.38 \pm 0.39$, respectively, the difference was statistically significant $(\mathrm{P}<0.05)$. The expression levels of miR-195-5p in serum of RR group and non-RR group were $1.97 \pm 0.41$, $1.24 \pm 0.37$, the difference was statistically significant $(\mathrm{P}<0.05)$. The receiver operating characteristic (ROC) curve of the serum miR-493-5p and miR-195-5p expression levels in the diagnosis of patients was drawn. The AUC value of the serum miR-493-5p diagnosis was 0.829 , the sensitivity was $72 \%$, and the specificity was $85.92 \%$; the AUC of therapeutic effect of serum miR-195-5p was 8.95 , the sensitivity was $90.67 \%$, and the specificity was $71.83 \%$ (Fig. 2).

\section{Discussion}

$\mathrm{PCa}$ is one of the most common adult malignant tumors. Approximately 220,000 American males are diagnosed with PCa every year. Androgen deprivation therapy (ADT) is one of the main methods for PCa treatment. Male patients with metastatic $\mathrm{PCa}$ almost all develop drug resistance to primary ADT and develop CRPC $(18,19)$. In the past, treatment options for CRPC patients were limited. In recent years, new androgen pathway inhibitors are becoming the mainstream treatment methods for CRPC, such as abiraterone acetate and enzalutamide (20). At present, there is no unified administration method for treating CRPC through androgen pathway inhibitor clinically, and the curative effect and side effects by different administration methods are also different. It is of great significance for CRPC patients to explore the administration method with better curative effect and safety.

Serum PSA is widely used as a biomarker for $\mathrm{PCa}$ diagnosis and is also a powerful prognostic marker for $\mathrm{PCa}$ long-term risk $(21,22)$. Some studies $(23)$ show that the serum PSA level of CRPC patients has significantly decreased after using abiraterone acetate, and the early PSA change is related to the survival rate of patients using abiraterone acetate, i.e. the increase of early PSA leads to poor prognosis of early chemotherapy. The results of this study show that the serum PSA levels of the two groups of patients significantly decreased after treatment and the decrease in the study group was greater. Similar to the above results, it shows that the two administration methods in this study can effectively reduce PSA levels, and the administration method of abiraterone combined with flutamide could decrease the levels more quickly.

Abiraterone acetate is the nursing standard of CRPC, which can improve the overall survival time and progressionfree survival time of CRPC patients and reduce the deterioration of the quality of life in metastatic CRPC patients. Currently, abiraterone acetate has been approved by more than 70 countries (2014) for the treatment of metastatic CRPC patients who have not received chemotherapy $(24,25)$. Research (26) results show that abiraterone acetate also shows significant anti-tumor activity in CRPC patients after receiving docetaxel, and has good effects on safety and tolerance. Flutamide is the first nonsteroidal antiandrogen drug approved by the U.S. Food and Drug Administration (FDA) for $\mathrm{PCa}$, which can block the action of androgen testosterone, prevent normal growth of PCa cells and achieve the purpose 
A
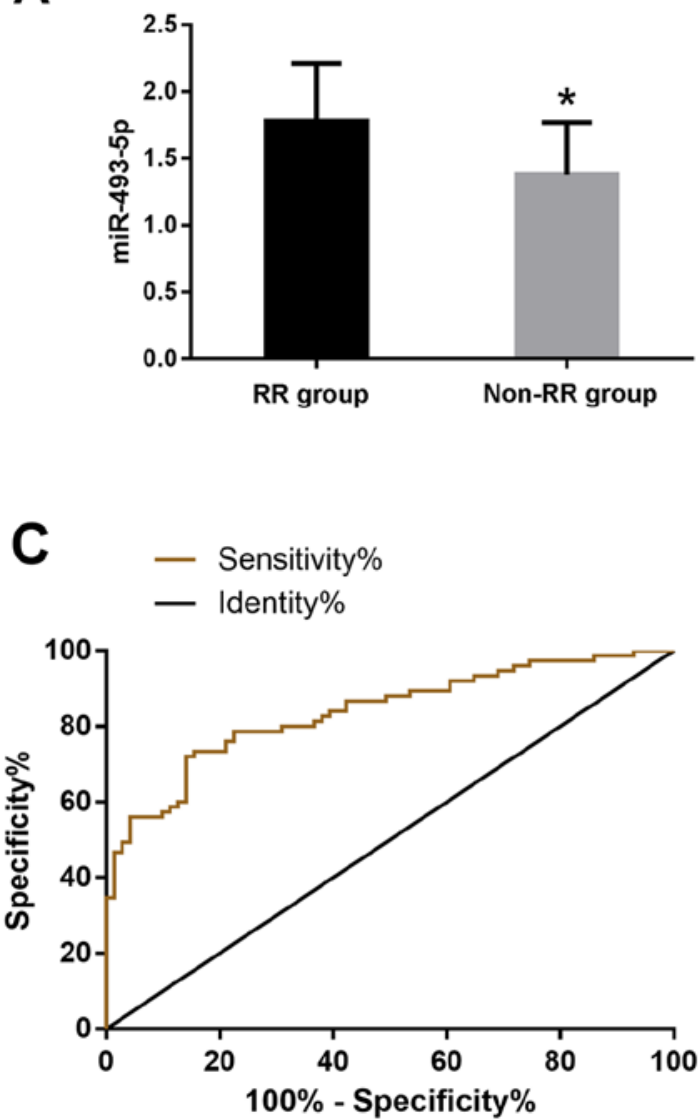

B
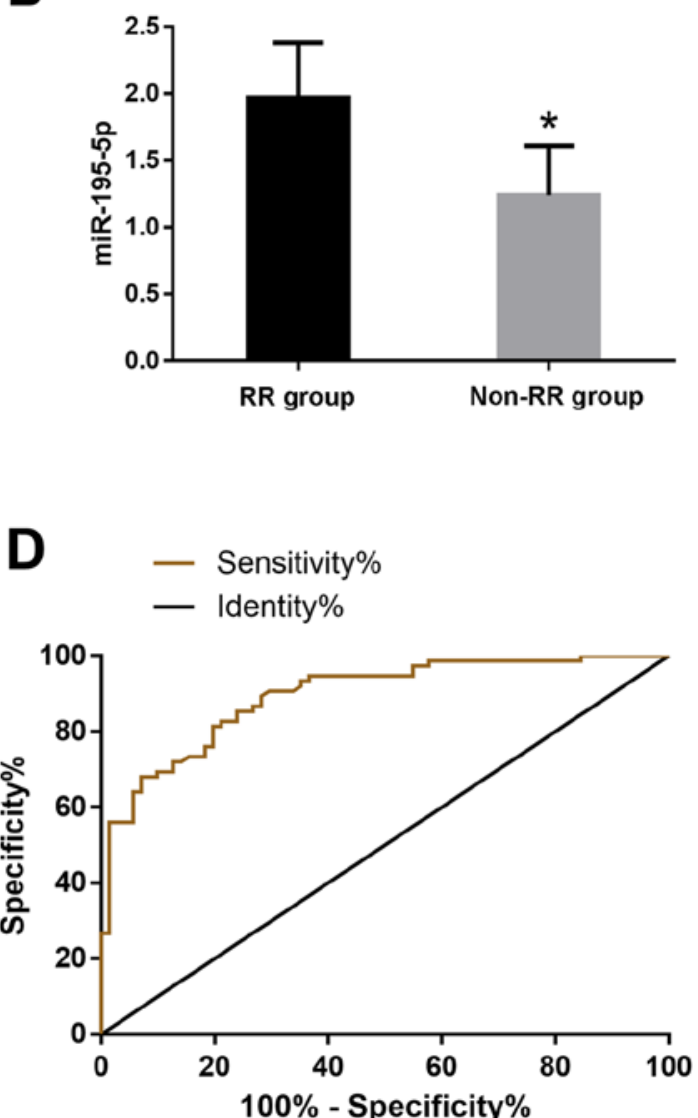

Figure 2. Diagnostic value of miR-493-5p and miR-195-5p expression levels in patients with therapeutic effects. (A) The expression level of miR-493-5p in serum of RR group was significantly higher than that of non-RR group $(P<0.05)$. (B) The expression level of miR-195-5p in serum of RR group was significantly higher than that of non-RR group $(\mathrm{P}<0.05)$. (C) ROC curve for the diagnosis of serum miR-493-5p in patients. (D) ROC curve for the diagnosis of serum miR-195-5p in patients. ROC, receiver operating characteristic; RR group, response rate group. * $\mathrm{P}<0.05$, compared with $\mathrm{RR}$ group.

of treating PCa (27). Basch et al (28) showed that compared with placebo combined with prednisone, abiraterone combined with prednisone can prolong the response pain progression and median time of CRPC patients undergoing chemotherapy treatment, and the median time for deterioration of health-related quality of life (HRQoL) is also longer. Fizazi et al (29) also used abiraterone combined with prednisone to treat CRPC patients. The results are similar to those of Basch et al (28). The median overall survival time and radiological progression-free survival time of patients in the abiraterone group (androgen deprivation therapy and abiraterone conbined with prednisone) are significantly longer than those in the placebo group (androgen deprivation therapy and double placebo), and other indicators observed in the abiraterone group are also better than those in the placebo group, such as the time of pain progression, subsequent PCa treatment, chemotherapy initiation and prostate specific antigen progression. In recent years, it has been reported that the use of carbamide and flutamide in patients with PCa prior to the use of abiraterone does not rule out the effects of abiraterone (30). The results of this study show that $\mathrm{RR}$ in the study group was significantly higher than that in the control group after treatment, the total incidence of toxic and side effects in the study group was significantly lower than that in the control group, and OS in the study group was significantly higher than that in the control group for 5 years. This indicates that abiraterone combined with flutamide has better curative effect and lower incidence of adverse reactions in CRPC patients than single drug.

Wang et al (31) showed that miR-493-5p is downregulated in PCa cells, c-Met, CREB1 and EGFR are downstream target genes of miR-493-5p, and miR-493-5p inhibits cancer development through AKT/GSK-3 $\beta /$ Snail signaling in prostate cancer. Cai et al (32) reported that the downregulation of miR-195-5p in PCa tissue is significantly related to high Gleason score, positive metastasis failure and biochemical recurrence, and they confirmed the tumor inhibitory effect of miR-195-5p through in vitro $\mathrm{PCa}$ cell invasion, migration and apoptosis experiments. Linder et al (33) also reached the same conclusion as Cai et al (32), that is, miR-195-5p can inhibit $\mathrm{PCa}$ tumor, overexpression of miR-195-5p can inhibit $\mathrm{PCa}$ cell migration, invasion and epithelial-mesenchymal transition (EMT). They also pointed out that fibroblast growth factor 2 (FGF2) is recognized as the direct target of miR-195-5p, and miR-195-5p can inhibit PCa cell metastasis by downregulating FGF2. After treatment, the relative expression of miR-493-5p and miR-195-5p in the serum of the two groups of patients in this study significantly increased. The above research shows that overexpression of miR-493-5p and miR-195-5p significantly inhibits the migration and invasion of PCa cells and 
acts as a tumor inhibitor in PCa cells. Therefore, we speculate that abiraterone and flutamide may inhibit the migration and invasion of PCa cells by increasing the expression levels of miR-493-5p and miR-195-5p and also their molecular mechanisms such as the antagonism of androgen receptor miR-195-5p, thus, reducing the progress of $\mathrm{PCa}$ and achieving the purpose of PCa treatment. At the end of the study, we also examined the diagnostic value of miR-493-5p and miR-195-5p expression levels in patients. The results showed that the AUC values of the therapeutic effects of serum miR-493-5p and miR-195-5p were respectively 0.829 and 0.895 , indicating that they both have a certain diagnostic value for the efficacy of PCa.

Collectively, abiraterone combined with flutamide has better curative effect and lower incidence of adverse reactions in CRPC patients than single drug, and can increase the expression levels of miR-493-5p and miR-195-5p in patient serum.

\section{Acknowledgements}

Not applicable.

\section{Funding}

No funding was received.

\section{Availability of data and materials}

The datasets used and/or analyzed during the present study are available from the corresponding author on reasonable request.

\section{Authors' contributions}

CY and YD conceived and designed the study, and drafted the manuscript. CY, YD, SP and XG collected, analyzed and interpreted the experimental data. $\mathrm{XG}$ revised the manuscript for important intellectual content. All authors read and approved the final manuscript.

\section{Ethics approval and consent to participate}

The study was approved by the Ethics Committee of Longhua Hospital Shanghai University of Traditional Chinese Medicine (Shanghai, China). Signed informed consents were obtained from the patients and/or guardians.

\section{Patient consent for publication}

Not applicable.

\section{Competing interests}

The authors declare that they have no competing interests.

\section{References}

1. Afshar-Oromieh A, Holland-Letz T, Giesel FL, Kratochwil C, Mier W, Haufe S, Debus N, Eder M, Eisenhut M, Schäfer M, et al: Diagnostic performance of 68Ga-PSMA-11 (HBED-CC) PET/CT in patients with recurrent prostate cancer: Evaluation in 1007 patients. Eur J Nucl Med Mol Imaging 44: 1258-1268, 2017.
2. Watson PA, Arora VK and Sawyers CL: Emerging mechanisms of resistance to androgen receptor inhibitors in prostate cancer. Nat Rev Cancer 15: 701-711, 2015.

3. Yang Y, Chen R, Sun T, Zhao L, Liu F, Ren S, Wang H, Lu X, Gao X, Xu C, et al: Efficacy and safety of combined androgen blockade with antiandrogen for advanced prostate cancer. Curr Oncol 26: e39-e47, 2019.

4. Kambale PR, Haldar D, Kabi BC and Kambale KP: Study of vitamin D receptor gene polymorphism (FokI, TaqI and ApaI) among prostate cancer patients in North India. J Clin Diagn Res 11: BC05-BC08, 2017.

5. Benoist GE, Hendriks RJ, Mulders PF, Gerritsen WR, Somford DM, Schalken JA, van Oort IM, Burger DM and van Erp NP: Pharmacokinetic aspects of the two novel oral drugs used for metastatic castration-resistant prostate cancer: Abiraterone acetate and enzalutamide. Clin Pharmacokinet 55: 1369-1380, 2016.

6. Yasui M, Uemura K, Yoneyama S, Kawahara T, Hattori Y, Teranishi JI, Inoue M, Ohta JI, Yokomizo Y, Yao M, et al: Predictors of poor response to secondary alternative antiandrogen therapy with flutamide in metastatic castration-resistant prostate cancer. Jpn J Clin Oncol 46: 1042-1046, 2016.

7. Reid AH, Attard G, Danila DC, Oommen NB, Olmos D, Fong PC, Molife LR, Hunt J, Messiou C, Parker C, et al: Significant and sustained antitumor activity in post-docetaxel, castrationresistant prostate cancer with the CYP17 inhibitor abiraterone acetate. J Clin Oncol 28: 1489-1495, 2010.

8. de Bono JS, Logothetis CJ, Molina A, Fizazi K, North S, Chu L, Chi KN, Jones RJ, Goodman OB Jr, Saad F, et al; COU-AA-301 Investigators: Abiraterone and increased survival in metastatic prostate cancer. N Engl J Med 364: 1995-2005, 2011.

9. Iguchi T, Tamada S, Kato M, Yasuda S, Otoshi T, Hamada K, Yamasaki T and Nakatani T: Enzalutamide versus flutamide for castration-resistant prostate cancer after combined androgen blockade therapy with bicalutamide: A retrospective study. Int J Clin Oncol 24: 848-856, 2019.

10. Fukasawa S, Suzuki H, Kawaguchi K, Noguchi H, Enjo K, Tran N, Todd M, Fizazi K and Matsubara N: Efficacy and safety of abiraterone acetate plus prednisone in Japanese patients with newly diagnosed, metastatic hormone-naïve prostate cancer: A subgroup analysis of LATITUDE, a randomized, doubleblind, placebo-controlled, Phase 3 study. Jpn J Clin Oncol 48: 1012-1021, 2018.

11. Nie W, Ge HJ, Yang XQ, Sun X, Huang H, Tao X, Chen WS and Li B: LncRNA-UCA1 exerts oncogenic functions in non-small cell lung cancer by targeting miR-193a-3p. Cancer Lett 371: 99-106, 2016.

12. Fernandez S, Risolino M, Mandia N, Talotta F, Soini Y, Incoronato M, Condorelli G, Banfi S and Verde P: miR-340 inhibits tumor cell proliferation and induces apoptosis by targeting multiple negative regulators of p27 in non-small cell lung cancer. Oncogene 34: 3240-3250, 2014.

13. Beebe-Dimmer JL, Ruterbusch JJ, Bylsma LC, Gillezeau C, Fryzek J, Schultz NM, Flanders SC, Barlev A, Heath E and Quek RGW: Patterns of bicalutamide use in prostate cancer treatment: A U.S. real-world analysis using the SEER-Medicare database. Adv Ther 35: 1438-1451, 2018.

14. Zhao L, Feng X, Song X, Zhou H, Zhao Y, Cheng L and Jia L: miR-493-5p attenuates the invasiveness and tumorigenicity in human breast cancer by targeting FUT4. Oncol Rep 36: 1007-1015, 2016.

15. Wang G, Fang X, Han M, Wang X and Huang Q: MicroRNA493-5p promotes apoptosis and suppresses proliferation and invasion in liver cancer cells by targeting VAMP2. Int J Mol Med 41: 1740-1748, 2018.

16. Eisenhauer EA, Therasse P, Bogaerts J, Schwartz LH, Sargent D, Ford R, Dancey J, Arbuck S, Gwyther S, Mooney M, et al: New response evaluation criteria in solid tumours: Revised RECIST guideline (version 1.1). Eur J Cancer 45: 228-247, 2009.

17. Tamada S, Iguchi T, Kato M, Asakawa J, Kita K, Yasuda S, Yamasaki T, Matsuoka Y, Yamaguchi K, Matsumura K, et al: Time to progression to castration-resistant prostate cancer after commencing combined androgen blockade for advanced hormone-sensitive prostate cancer. Oncotarget 9: 36966-36974, 2018.

18. Teoh JY, Ng CF and Poon DM: Chemohormonal therapy for metastatic hormone-sensitive prostate cancer: An Asian perspective. Asia Pac J Clin Oncol 14 (Suppl 5): 5-8, 2018. 
19. Robinson D, Van Allen EM, Wu YM, Schultz N, Lonigro RJ, Mosquera JM, Montgomery B, Taplin ME, Pritchard CC, Attard G, et al: Integrative clinical genomics of advanced prostate cancer. Cell 161: 1215-1228, 2015.

20. Mittal RD, Mishra DK, Srivastava P, Manchanda P, Bid HK and Kapoor R: Polymorphisms in the vitamin D receptor and the androgen receptor gene associated with the risk of urolithiasis. Indian J Clin Biochem 25: 119-126, 2010.

21. Dong L, Zieren RC, Xue W, de Reijke TM and Pienta KJ: Metastatic prostate cancer remains incurable, why? Asian J Urol 6: 26-41, 2019.

22. Shariat SF, Semjonow A, Lilja H, Savage C, Vickers AJ and Bjartell A: Tumor markers in prostate cancer I: Blood-based markers. Acta Oncol 50 (Suppl 1): 61-75, 2011.

23. Rescigno P, Lorente D, Bianchini D, Ferraldeschi R, Kolinsky MP, Sideris S, Zafeiriou Z, Sumanasuriya S, Smith AD, Mehra N, et al: Prostate-specific antigen decline after 4 weeks of treatment with abiraterone acetate and overall survival in patients with metastatic castration-resistant prostate cancer. Eur Urol 70: 724-731, 2016

24. Szmulewitz RZ, Peer CJ, Ibraheem A, Martinez E, Kozloff MF, Carthon B, Harvey RD, Fishkin P, Yong WP, Chiong E, et al: Prospective international randomized phase II study of low-dose abiraterone with food versus standard dose abiraterone in castration-resistant prostate cancer. J Clin Oncol 36: 1389-1395, 2018.

25. Nagai T, Naiki T, Iida K, Etani T, Ando R, Hamamoto $\mathrm{S}$, Sugiyama Y, Akita H, Kubota H, Hashimoto Y, et al: Early abiraterone acetate treatment is beneficial in Japanese castrationresistant prostate cancer after failure of primary combined androgen blockade. Prostate Int 6: 18-23, 2018.

26. Xu L, Chen J, Liu W, Liang C, Hu H and Huang J: Targeting androgen receptor-independent pathways in therapy-resistant prostate cancer. Asian J Urol 6: 91-98, 2019.

27. Ito $\mathrm{Y}$ and Sadar MD: Enzalutamide and blocking androgen receptor in advanced prostate cancer: Lessons learnt from the history of drug development of antiandrogens. Res Rep Urol 10: 23-32, 2018
28. Basch E, Autio K, Ryan CJ,Mulders P, Shore N, Kheoh T, Fizazi K, Logothetis CJ, Rathkopf D, Smith MR, et al: Abiraterone acetate plus prednisone versus prednisone alone in chemotherapy-naive men with metastatic castration-resistant prostate cancer: Patientreported outcome results of a randomised phase 3 trial. Lancet Oncol 14: 1193-1199, 2013.

29. Fizazi K, Tran N, Fein L, Matsubara N, RodriguezAntolin A, Alekseev BY, Özgüroğlu M, Ye D, Feyerabend S, Protheroe A, et al; LATITUDE investigators: Abiraterone plus prednisone in metastatic, castration-sensitive prostate cancer. $\mathrm{N}$ Engl J Med 377: 352-360, 2017.

30. Zhao JG, Liu JD, Shen PF, Tang X, Sun GX, Zhang XM, Chen JR, Shu KP, Shi M and Zeng H: Prior switching to a second-line nonsteroidal antiandrogen does not impact the therapeutic efficacy of abiraterone acetate in patients with metastatic castration-resistant prostate cancer: A real-world retrospective study. Asian J Androl 20: 545-550, 2018.

31. Wang S, Wang X, Li J, Meng S, Liang Z, Xu X, Zhu Y, Li S, $\mathrm{Wu} \mathrm{J}, \mathrm{Xu} \mathrm{M}$, et al: c-Met, CREB1 and EGFR are involved in miR-493-5p inhibition of EMT via AKT/GSK-3 $\beta /$ Snail signaling in prostate cancer. Oncotarget 8: 82303-82313, 2017.

32. Cai C, Chen QB, Han ZD, Zhang YQ, He HC, Chen JH, Chen YR, Yang SB, Wu YD, Zeng YR, et al: miR-195-5 inhibits tumor progression by targeting RPS6KB1 in human prostate cancer. Clin Cancer Res 21: 4922-4934, 2015.

33. Linder S, van der Poel HG, Bergman AM, Zwart W and Prekovic S: Enzalutamide therapy for advanced prostate cancer: Efficacy, resistance and beyond. Endocr Relat Cancer 26: R31-R52, 2018.

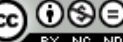

This work is licensed under a Creative Commons Attribution-NonCommercial-NoDerivatives 4.0 International (CC BY-NC-ND 4.0) License. 